\title{
Bazı sofralık üzüm çeşitlerinin Antalya'daki değişik yörelere uygunlukları ve etkili sıcaklık toplamı istekleri
}

\section{Effective heat summation requirements and matching to different sites of table grape cultivars in Antalya}

\author{
Burak AKTÜRK(i), Halil İbrahim UZUN(i) \\ Akdeniz Üniversitesi, Ziraat Fakültesi, Bahçe Bitkileri Bölümü, 07070, Antalya \\ Sorumlu yazar (Corresponding author): B. Aktürk, e-posta (e-mail): akturkbrk@gmail.com \\ Yazar(lar) e-posta (Author e-mail): uzun@akdeniz.edu.tr
}

\section{MAKALE BİLGİSİ}

Alınıș tarihi 31 Ocak 2019

Düzeltilme tarihi 17 Eylül 2019

Kabul tarihi 18 Eylül 2019

\section{Anahtar Kelimeler:}

EST

Vitis vinifera

Fenoloji

Yöre

\section{ÖZ}

Bu çalışma, Akdeniz Üniversitesi Ziraat Fakültesindeki bağlarda yetiştirilmekte olan 34 sofralık üzüm çeşidi ile 2017 yılında yürütülmüştür. Her bir çeşit için fenolojik evreler gözlemlenmiş; üzüm çeşitlerinin etkili sıcaklık toplamı (EST) istekleri ve fenolojik evreleri arasındaki gün sayıları belirlenmiştir. Ayrıca, Meteoroloji Genel Müdürlüğünün Antalya ilinde farklı rakımlarda bulunan 35 yöredeki istasyonlarından alınan günlük hava sıcaklığı verileri kullanılarak, yörelerin EST potansiyelleri hesaplanmıştır. Her bir çeşidin o yöreye uygunluğunu belirlemek amaciyla, üzüm çeşitlerinin EST istekleri ile yörelerin EST potansiyelleri karşılaştırılmıştır. Çok yüksek rakımlı yerler hariç; çoğu yörenin hava sıcaklığı açısından, doğru çeşit seçildiği takdirde, sofralık üzüm yetiştiriciliğine uygun olduğu belirlenmiștir. En erkenci üzüm çeşidinin 925 derece gün (dg) ile Early Sweet ve en geççi çeşidin 2127 dg ile Reçel Üzümü olduğu belirlenmiştir. Yörelerin EST potansiyellerinin ise 409-3360 dg arasında değiştiği saptanmıştır. Araştırma bağının bulunduğu yörenin EST potansiyeli $3360 \mathrm{dg}$ olarak belirlenmiștir. Uyanmadan olgunlaşmaya kadar geçen gün sayıs1, 101 gün ile Prima ve Trakya İlkeren'de en kısa; 158 gün ile Kara Erik çeşidinde en uzun olmuștur. Early Sweet çeșidi, çok düşük EST isteği ile Antalya'da haziran ayı ortasında olgunlaşan oldukça erkenci bir çeşit olarak dikkati çekmiştir. Bu çeşit özellikle, kısa yetişme mevsimi olan yüksek rakımlı yerler ile erkencilik amaçlı yetiştiricilik yapılan düşük rakımlı yerler için öncelikle önerilmiştir.

\section{ARTICLE INFO}

Received 31 January 2019

Received in revised form 17 September 2019 Accepted 18 September 2019

\section{Keywords:}

EHS

Vitis vinifera

Phenology

Location

\begin{abstract}
This research was carried out in 2017 with 34 table grape cultivars which are being cultivated in the vineyards of the Faculty of Agriculture at Akdeniz University in Antalya. The phenological stages were observed for each cultivar. Effective heat summation (EHS) requirements and number of days between phenological stages of grape cultivars were determined. EHS potentials of 35 locations at different elevations in Antalya were calculated by using daily air temperature data received from the meteorological stations of Turkish State Meteorological Service in each location. EHS requirements of grape cultivars and EHS potentials of locations were matched to detect the suitability of each cultivar to the location. Most of locations except extremely high elevated ones have convenient air temperature conditions for table grape cultivation if the right cultivars are selected. İn terms of EHS values between budburst and harvest date, the earliest cultivar was Early Sweet with 925 degree days (dd) and the last matured cultivar was Reçel Üzümü with 2127 dd. EHS potentials of locations changed between 409 and $3360 \mathrm{dd}$. EST potential of experimental vineyard location was 3360 dd. Number of days from bud burst to harvest date ranged from 101 days in Prima and Trakya Ilkeren to 158 days in Kara Erik. The most noticeable cultivar was Early Sweet with very low EHS value which has extremely earliest ripening time at mid-June in Antalya. It can particularly be recommended for low elevated locations for earliness and for high elevated locations with short growing season.
\end{abstract}




\section{Giriş}

Üzüm yetiştiriciliği, yurdumuzun tamamına yakın bölümünde ve değişik ekolojilerde, çok uzun geçmişe dayanan önemli bir tarım koludur. Bir yörede bağcılık yapılıp yapılamayacağını saptamanın en pratik yolu, asmanın o yörede üzümlerini olgunlaştırabilmesi için ihtiyaç duyduğu sıcaklık toplamının karşılanıp karşılanamayacağının belirlenmesidir. Bağcılıkta bu amaçla kullanılan en yaygın yöntem, etkili sıcaklık toplamı (EST) değerinin saptanmasıdır (Winkler ve ark. 1974). Bir yörenin potansiyel EST değeri, genelde asmada gözlerin uyanmaya başladığı nisan ayı ile sonbaharda erken donların başladığı ekim sonu arasında kalan, kuzey yarımkürede 1 Nisan-31 Ekim tarihleri arasındaki dönem için hesaplanmaktadır. Bu amaçla, günlük ortalama hava sıcaklıkları değerinden, asmada gözlerin uyanmaya başladığı eşik sıcaklık değeri olan $10^{\circ} \mathrm{C}$ 'nin çıkarılması ile o güne ait etkili sıcaklık değeri bulunmaktadır. Bu değer, 1 Nisan-31 Ekim tarihleri arasında kalan her bir gün için hesaplanarak toplanmakta ve o yörenin EST potansiyeli belirlenmektedir. Bu tarihlerin esas alınmasının nedeni, kuzey yarımkürede bağcılık kuşağı kabul edilen 20-50. enlem dereceleri arasinda vejetasyon periyodunun genellikle bu tarihler arasında meydana gelmesidir (Çelik 2007). Diğer taraftan, yurdumuzda ekim sonundan itibaren sonbahar erken donları başlamaktadır. Bu nedenle, özellikle sonbahar erken don riskinin olduğu yörelerde, üzümlerin olgunlaşmasını sonbahar erken donları başlamadan ve en geç ekim sonunda tamamlanması istenir (Uzun 2006). Dolayısıyla bir yörenin EST potansiyelinin ölçümü, o yörede asmaların yaklaşı uyanma tarihi ile sonbahar erken donlarının başlama zamanı arasında kalan dönem için hesaplanmalıdır. EST değerinin birimi, İngilizce karşılığının (degree-days) Türkçeye çevirisi olan derece gün (dg)'dür. Fakat bazı araştırıcılar tarafından gün derece şeklinde de kullanılmaktadır (Çelik ve ark. 1998). Oysa bunu, orijinaline sadık kalınarak, derece gün şeklinde ifade etmek daha doğru olacaktır. Günlük EST değeri, Winkler ve ark. (1974) tarafından belirtildiği gibi, günlük maksimum hava sıcaklığı değerinden, günlük minimum değer çıkarılıp ikiye bölünerek günlük ortalama hava sıcaklığı bulunmakta ve bundan eşik değer çıkarılarak hesaplanmaktadır. Ancak, gelişen dijital sıcakl1k kaydedici cihazlarla, saatlik olarak yapılan kayıtların ortalaması alınarak da, günlük ortalama hava sıcaklıklarının daha kesin hesaplanabileceği belirtilmiştir $(\mathrm{Gu}$ 2016). Böylece, EST değerleri daha hassas ve sağlıklı ölçülebilmektedir. EST değeri, yörenin EST potansiyeli ve üzüm çeşidinin EST isteği olmak üzere iki farklı şekilde hesaplanır. Bir yörenin EST değerinin hesaplanmasında 1 Nisan-31 Ekim tarihleri arasındaki dönemi esas alınır (Winkler ve ark. 1974). Bir üzüm çeşidinin EST değerinin saptanmasında ise o çeşidin gözlerinin uyanmasından, üzümlerinin olgunlaşmasına kadar, başka bir ifadeyle hasat tarihine kadar geçen dönemdeki hava sıcaklıkları esas alınır. Bu nedenle, bir yörenin EST potansiyelinin hesaplaması için en doğru dönem; o yörede asmaların uyanma zamanı ile sonbahar erken donlarının başladığı zaman arasında kalan dönem olması gerekir. Örneğin Van yöresinde asmaların mayıs başında uyandığı belirtilmiştir (Gazioğlu Şensoy ve ark. 2009). Bu durumda Van gibi soğuk yörelerin EST potansiyelini mayıs ayından itibaren, sonbahar erken donlarının başladığı tarihe hesaplamak gerekir. Antalya koşullarında asmalarda uyanmanın, sahilden yaylalara doğru, mart ortasından nisan ortasına kadar süren yaklaşık 1 aylık bir dönemde gerçekleştiği gözlenmiştir. Yörenin EST potansiyelinin ve çeşidin EST isteğinin hesaplanmasının amacı, o yörede üzüm çeşitlerinin olgunlaşabilmesi için ihtiyaç duyduğu sıcaklık toplamının, sonbahar erken donları başlamadan önce, karşıllanıp karşıllanamayacağını belirlemektir. Dolayısıyla pratikteki amacı, sıcaklık toplamı açısından o yöre için en uygun üzüm çeşitlerinin seçimini sağlamaktır. Ayrıca, üzümlerin o yörede yaklaşık hangi tarihte olgunlaşacağının tahmin edilebilmesi, pazarlama, işgücü talebi, kültürel işlemlerin düzenlenmesi gibi bağda yapılacak işlerin yönetilmesine de yardımcı olacaktır. Bir çeşidin o yöreye uygun olabilmesi için, başka bir ifade ile çeşidin o yörede üzümlerini olgunlaştırabilmesi için çeşidin EST değerinin, yörenin EST değerinden daha düşük olması gerekir. Ülkemiz koşullarında bu durum, daha çok yüksek rakımlı yayla yerlerde veya soğuk bölgelerde çeşit seçiminde daha da önem kazanmaktadır. Üzüm çeşitleri, erkencilerden geççilere doğru gittikçe artan EST isteğine sahiptir. Ülkemizde yetiştirilen birçok üzüm çeşidinin değişik yörelerdeki EST istekleri konusunda çok sayıda çalışma yapılmıştır (Uzun ve ark. 1995; Uzun 1997; Kök ve Çelik 2003; Çelik ve ark. 2005; Özdemir ve Tangolar 2005; Gazioğlu Şensoy ve ark. 2009; Sağlam ve ark. 2009; Kamiloğlu ve ark. 2014; Köse 2014; Altun 2015; Kaya ve Özdemir 2015; Sögüt ve Özdemir 2015).

Bir yörede ekonomik anlamda bağcılık yapılabilmesi için o yörenin 1 Nisan-31 Ekim tarihleri arasındaki EST değerinin minimum 900 dg olması gerektiği belirtilmiştir (Çelik ve ark. 1998). Bunun nedeni, en erkenci çeşitlerin bile üzümlerini olgunlaştırabilmesi için asgari $900 \mathrm{dg}$ EST değerine ihtiyaç duymasıdır. Bir çeşidin ihtiyaç duyduğu EST değeri yıllara veya ekolojilere göre az çok farklılık gösterebilmektedir. Çelik ve ark. (2005), Kalecik'te yetiştirilen üzüm çeşitlerindeki EST değerlerinin, Ankara merkezdekilere göre \%10-15 daha yüksek olduğunu saptamıştır. Bazen bu farklılıkların ortaya çıkmasında, gözlerin uyanmasında veya çeşidin olgunluk tarihinin saptanmasında, araştırıcılar tarafından farklı yöntemlerin kullanması da etkili olabilmektedir. Bu nedenle, çeşitlerin özellikle olgunlaşma tarihinin saptanmasında standart bir yöntem veya olgunluk indisinin esas alınmasında yarar vardır. İnsan hatasından kaynaklanan farklılıkları azaltmak için, değişik araştırıcılar tarafından yapılan çalışmalarda kullanılan fenolojik tarihleri tespit yöntemlerinin de, her bir yayında ayrıntılı bir şekilde açıklanması gerekmektedir. Uyanma veya hasat tarihlerinin belirlenmesinde, hesaplama hatasından kaynaklanan birkaç günlük değişim; o çeşidin gerçek EST değerinin saptanmasında da hatalara yol açacaktır. Çeşitlerin uyanma tarihlerinin saptanmasında, uluslararası bağcılık ve şarapçılık organizasyonu (OIV) tarafindan önerilen (OIV kod no: 301), bir asmadaki gözlerin \%50 sinde yeşil aksamın ilk gözüktüğü (Baggiolini C veya BBCH 7-9 skalası) evre esas alınmalıdır (OIV 2001). Olgunlaşma tarihi olarak, OIV tarafindan tanelerde maksimum şeker içeriğine ulaşıldığ tarih önerilmiştir (OIV kod no:304). Ancak, bu tarih daha çok şaraplık üzümler için geçerlidir. Oysa sofralık üzümler, genellikle maksimum şeker değerine ulaşmadan hasat edilir ve olgunlaşmada daha çok olgunluk indisi değerleri esas alınır. Olgunluk indisi tanedeki \% suda çözülebilir kuru madde miktarının (SÇKM; genel kullanımıyla şeker miktarının), \% asit değerine oranlanması ile hesaplanır (Uzun 2006). Sofralık üzümler için Codex alimentarius'da minimum olgunluk indisi değerleri belirlenmiştir. Bunun için üzüm tanelerinin en az \%16 SÇKM değerine sahip olması istenmektedir. Ancak daha düşük SÇKM'de hasat edileceklerde minimum olgunluk indisinin; SÇKM miktarı \%12.5-<\%14 olanlar için 20:1; SÇKM miktarı $\% 14-<\% 16$ arasında olanlarda ise 18:1 olması gerekmektedir (FAO 2007). Oysa minimuma nazaran optimal olgunluk indisi değerleri daha yüksektir ve ülkemizdeki sofralık üzümlerde genellikle 30-40/1 arasında değişmektedir (Tangolar ve ark. 
2002). Bu nedenle en uygun hasat zamanının başlangıcı olarak optimal olgunluk indisinin 30/1 olduğu zamanı, EST çalışmalarında, hasat tarihinde standardizasyonu sağlamak amacıyla, sofralık üzümlerin olgunlaşma tarihi olarak kabul etmek daha uygun olacaktır. Böylece, sofralık üzümlerde EST ile ilgili çalışmalarda, hasat tarihinin saptanması yönteminde eşgüdüm sağlanmış olur ve ölçüm yönteminden kaynaklanan hataların da önüne geçilmiş ve çeşitlerin gerçek EST isteği saptanmış olur. Diğer taraftan hasat tarihinin saptanmasında yapılan genel hatalardan biri de, analiz yapılacak üzüm örneklerinin alınma şeklidir. Bu amaçla çok değişik yöntemler kullanılmaktadır. Fakat bu çalışmalar, daha çok şaraplık üzüm çeşitleri ve büyük bağlardan örnek alınması konusundadır (Amerine ve Roessler 1958). Ancak daha küçük araştırma bağlarında örnek sayısı azaltılabilir. Bu açıdan OIV tarafından 10 sürgündeki salkımlar esas alınmaktadır (OIV 2001). Pratik olması açısından asmaların sağ ve sol tarafindan alınan asgari 10 salkımdaki tanelerde ölçüm yapılabilir. Üzüm taneleri; ya salkımların değişik yönlerinden ve orta kısımlarından alınmalı ya da salkımın uç, orta ve dip kısımlarından eşit sayıda olacak şekilde, toplam asgari 30 tane alınarak analizleri yapılmalıdır. Diğer taraftan, örnek alınacak salkım veya tane sayısı ne kadar fazla olursa, ölçümdeki hata payı da o derece azalacaktır.

$\mathrm{Bu}$ çalışmanın amacı; Antalya ili merkezinde yer alan Akdeniz Üniversitesi Ziraat Fakültesi araştırma ve koleksiyon bağlarında mevcut bazı üzüm çeşitlerinin; Antalya ekolojik koşullarındaki fenolojik özelliklerini tespit etmek, üzümlerin olgunlaşabilmeleri için ihtiyaç duydukları EST değerlerini saptamak, Antalya ili genelinde yer alan meteoroloji istasyonlarının bulunduğu farklı rakımdaki yörelerin potansiyel EST değerlerini belirlemek ve o yörelerin, hangi üzüm çeşitlerinin yetiştirilmesine uygun olduğunu tespit etmektir.

\section{Materyal ve Yöntem}

\subsection{Materyal}

\subsubsection{Bitkisel materyal ve araştırma bă̆g}

Üzüm çeşitlerinin EST isteklerinin belirlenmesi çalışması Akdeniz Üniversitesi Ziraat Fakültesi Araştırma ve Koleksiyon Bağlarında 2017 yılında yürütülmüştür. Bitkisel materyal olarak Alphonse Lavallee, Amasya Beyazı, Atasarısı, Autumn Royal, Black Magic, Cardinal, Çavuş, Çınarlı Karası, Early Sweet, Flame Seedless, Hafizali, Hamburg Misketi, İtalia, K-7, Kabarcık, Kara Erik, Kozak Beyazı, Kozak Siyahı, Michelle Palieri, Muscat Bleu, Muscat Reine des Vignes, Perlette, Prima, Reçel Üzümü, Red Globe, Regent, Sultani Çekirdeksiz, Superior Seedless, Thompson Seedless, Trakya İlkeren, Uslu, Verigo, Victoria ve Yalova İncisi olmak üzere toplam 34 üzüm çeşidi kullanılmıştır. Araştırmanın yürütüldüğü bağlar, sahilden yaklaşık $5 \mathrm{~km}$ içeride, $50 \mathrm{~m}$ rakımlı, traverten yapıya sahip bir arazi üzerine tesis edilmiştir. Asmalar 99R anaci üzerine aşılanmış veya kendi kökleri üzerinde yetiştirilmiştir. Bağların bakım işlemleri düzenli olarak gerçekleştirilmiş; kısa budanan asmalara Avustralya sistemi, uzun budanan asmalara ise çift $\mathrm{T}$ terbiye sistemi uygulanmıştır. Yalova İncisi ise çardak terbiye sisteminde yetiştirilmiştir. $\mathrm{Bu}$ nedenle, anacın veya terbiye sistemlerinin fenolojik evrelere olası etkisi göz ardı edilmiştir. Dolayısıyla çeşitleri karşılaştırmak amacıyla istatistiki bir analizden de kaçınılmıştır.

\subsubsection{Meteorolojik veriler}

Üzüm çeşitlerinin EST isteklerinin belirlenmesinde kullanılan günlük hava sıcaklığı değerleri, deneme bağı içinde bulunan meteoroloji siperine yerleştirilmiş sıcaklık ve nem veri kayılt cihazından temin edilmiştir (Extech 42270). Günlük ortalama hava sıcaklıkları, her saat başı alınan değerlerin ortalaması alınarak hesaplanmıştır $\left(\mathrm{T}_{\text {ort }}\right)$. Deneme bağı dışındaki yörelere ait sicaklı verileri, Meteoroloji 4. Bölge Müdürlüğü'nün Antalya il sınırları içerisinde aktif olarak rasat yapılan farklı yer ve rakımlardaki 34 meteoroloji istasyonundan, günlük ortalama hava sıcaklık değerleri olarak temin edilmiştir.

\subsection{Yöntem}

\subsubsection{EST değerlerinin saptanmast}

Araştırmada yer alan çeşitler ve yöreler için EST değerlerinin belirlenmesinde, Winkler ve ark. (1974) tarafından bildirilen aşağıdaki eşitlikten faydalanılmıştır:

$$
\mathrm{EST}=\sum\left(\mathrm{T}_{\text {ort }}-\mathrm{T}_{\text {eşik }}\right)
$$

$\mathrm{T}_{\text {ort }}=$ Günlük ortalama hava sıcaklıkları $\left({ }^{\circ} \mathrm{C}\right)$

$\mathrm{T}_{\text {eşik }}=$ Gözlerin uyanmaya başladığ 1 hava sıcaklığ $1\left(10^{\circ} \mathrm{C}\right)$

EST istekleri üzüm çeşitleri için, gözlerin uyandığı tarihten hasadın gerçekleştiği tarihe kadar olan süre boyunca; yöre potansiyelleri ise, 1 Nisan-31 Ekim tarihleri arasindaki dönemde günlük ortalama hava sıcaklıklarının yukarıda belirtilen eşitliğe göre hesaplanmıştır. Her iki hesaplamada da

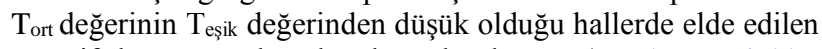
negatif değer, genel toplamdan çıkarılmıştır (Jacob ve Winkler 1950).

\subsubsection{Fenolojik parametrelerin saptanmasl}

Araştırmada incelenen fenolojik parametreler: uyanma, tam çiçeklenme, ben düşme ve hasattır. Ayrıca, olgunluk indisini belirlemek amaciyla tanelerde suda çözünür kuru madde (SÇKM) ve titre edilebilir asit (TEA) miktarları saptanmıştır. İncelenen çeşitlere ait fenolojik parametrelerin ölçülmesinde OIV tarafindan bildirilen ölçüm ve gözlem yöntemlerine uyulmuştur (OIV 2001). SÇKM ve TEA miktarları Cemeroğlu (2007) tarafindan belirtilen yöntemlere göre ölçülmüştür. Çeşitlerin hasat tarihleri ise Uzun (2006) tarafindan bildirildiği şekilde; SÇKM (\%) değerinin, TEA (\%) değerine oranlanması ile saptanan olgunluk indisi değerinin 30/1 olduğu tarih olarak kabul edilmiştir.

\section{Bulgular ve Tartışma}

\subsection{Fenolojik evreler ve üzüm çeşitlerinin EST istekleri}

Araştırmada incelen çeşitlerin tamamında uyanma evresinin mart ayı içinde gerçekleştiği tespit edilmiş, ilk uyanan çeşit "Early Sweet", son uyanan çeşitler ise "Prima" ve "İtalia" olarak saptanmıştır. Tam çiçeklenme evresi, 19 Nisan'da "Early Sweet" çeşidi ile başlamış ve mayıs ayının ikinci haftasında "Autumn Royale" ve "Michelle Palieri" çeşitleriyle sonlanmıştır. Ben düşme evresi ise ilk olarak "Early Sweet" çeşidinde, son olarak "Kara Erik" çeşidinde gözlenmiştir. İlk 
hasat 24 Haziran'da "Earyl Sweet" çeşidinde, son hasat 21 Ağustos'ta "Reçel Üzümü" çeşidinde yapılmıştır. Tüm evreler en erken 'Early Sweet' çeşidinde gerçekleşmiştir. Çeşitlerde uyanmadan olgunlaşmaya kadar geçen sürenin 101-158 gün arasında değiştiği tespit edilmiştir (Çizelge 1).

Denemenin yapıldığı bağda, Uzun ve ark. (1995) ile Uzun (1997) tarafindan daha önceden yürütülmüş olan çalışmalarda bildirilmiş fenolojik evre gerçekleşme tarihlerinin bu çalışmada saptananlar ile yakın olduğu görülmüştür. Aynı araştırıcıların bildirdiği evreler aras1 gün sayıs1 bakımından yapılan karşılaştırmada ise önceki çalışmalara nazaran 5-15 gün arasında değişen bir artışın söz konusu olduğu saptanmıştır. Bu farklılığın yıllar içerisinde değişkenlik gösteren hava sıcaklıklarından, asmanın ürün yükü ve bakım koşullarındaki farklılıklardan meydana gelmiş olabileceği düşünülmektedir.

Uyanma-olgunlaşma dönemi için en yüksek EST isteği 2127.22 dg ile "Reçel Üzümü", en düşük EST isteği ise 925.48 dg ile "Early Sweet" çeşidinde tespit edilmiştir. Çeşitlerin fenolojik evreler arası EST isteklerinde ise sırasıyla en düşük ve en yüksek değerler, uyanma-tam çiçeklenme için 294.49 dg
(Early Sweet)-454.56 dg (Michelle Palieri ve Autumn Royalle); tam çiçeklenme-ben düşme için $316.40 \mathrm{dg}$ (Yalova İncisi)861.55 dg (Kara Erik); ben düşme-olgunluk için 399.69 (Early Sweet)-1062.77 dg (Reçel Üzümü) olarak tespit edilmiştir (Çizelge 1). Çeşitlerin EST isteklerinin, aynı bağda daha önce yürütülmüş çalışmalarda bildirilenlerle benzer olduğu görülmüş, aradaki farklılıkların yıldan yıla değişiklik gösteren hava sıcaklıkları ve bakım koşullarından kaynaklandığı sonucuna varılmıştır (Uzun ve ark. 1995; Uzun 1997). Ayrıca, farklı ekolojilerde aynı çeşitlerle yapılan önceki çalışmalar incelendiğinde, çeşitlerin EST istekleriyle ilgili sıralamanın ekolojiden ekolojiye ve hatta aynı ekolojide bile yıllara göre değiştiği görülmüştür. Birbirinden oldukça farklı EST potansiyellerine sahip; Antalya, Kalecik, Van, Adana ve Diyarbakır ekolojilerinde; örneğin Cardinal ve Alphonse Lavalle çeşitlerinin EST istekleri incelendiğinde, çeşitlerin ekolojilere göre düzensiz seyreden EST değerlere sahip olduğu saptanmıştır. Söz konusu ekolojilerde en düşük EST değerine Cardinal Antalya'da sahip iken, Alphonse Lavallee Adana'da

Çizelge 1. Üzüm çeşitlerinin fenolojik evre tarihleri ve evreler arası geçen gün sayısı ile EST değerleri.

Table 1. Phenological dates, number of days and EHS values between phenological stages in grape varieties.

\begin{tabular}{|c|c|c|c|c|c|c|c|c|c|c|c|c|}
\hline \multirow[b]{2}{*}{ Çeşitler } & \multicolumn{4}{|c|}{ Fenolojik Evre Tarihleri* } & \multicolumn{4}{|c|}{ Evreler Arası Gün Sayısı } & \multicolumn{4}{|c|}{ Evreler aras1 EST istekleri (dg) } \\
\hline & $\mathrm{U}^{* *}$ & Ç** & $\mathrm{B} * *$ & $\mathrm{O} * *$ & $\mathrm{U}-\mathrm{C}$ & Ç-B & $\mathrm{B}-\mathrm{O}$ & $\mathrm{U}-\mathrm{O}$ & U-Ç & Ç-B & $\mathrm{B}-\mathrm{O}$ & $\mathrm{U}-\mathrm{O}$ \\
\hline Alphonse L. & 26.3 & 13.5 & 27.6 & 24.7 & 48 & 45 & 27 & 120 & 395.62 & 635.53 & 554.34 & 1585.48 \\
\hline Amasya Beyazı & 14.3 & 10.5 & 23.6 & 22.7 & 57 & 44 & 29 & 130 & 391.44 & 602.12 & 589.82 & 1583.38 \\
\hline Atasarıs1 & 25.3 & 11.5 & 10.6 & 18.7 & 47 & 30 & 38 & 115 & 372.06 & 377.94 & 723.84 & 1473.84 \\
\hline Autumn Royalle & 20.3 & 15.5 & 28.6 & 12.8 & 56 & 44 & 45 & 145 & 454.56 & 621.57 & 898.20 & 1974.33 \\
\hline Black Magic & 24.3 & 13.5 & 16.6 & 11.7 & 50 & 33 & 26 & 109 & 406.72 & 457.92 & 487.46 & 1352.10 \\
\hline Cardinal & 25.3 & 12.5 & 11.6 & 05.7 & 48 & 30 & 24 & 102 & 387.33 & 378.96 & 440.92 & 1207.20 \\
\hline Çavuş & 13.3 & 09.5 & 12.6 & 27.7 & 57 & 34 & 45 & 136 & 381.28 & 435.48 & 867.70 & 1684.46 \\
\hline Çınarlı Karası & 25.3 & 10.5 & 29.6 & 02.8 & 46 & 50 & 34 & 130 & 357.09 & 715.63 & 696.22 & 1768.93 \\
\hline Early Sweet & 01.3 & 19.4 & 24.5 & 16.6 & 49 & 35 & 23 & 107 & 294.49 & 358.76 & 399.69 & 925.48 \\
\hline Flame Seedless & 17.3 & 12.5 & 15.6 & 12.7 & 56 & 34 & 27 & 117 & 413.66 & 440.26 & 527.20 & 1381.13 \\
\hline Hafizali & 12.3 & 09.5 & 13.6 & 20.7 & 58 & 35 & 37 & 130 & 381.23 & 449.10 & 716.30 & 1546.63 \\
\hline Hamburg Misketi & 15.3 & 07.5 & 10.6 & 14.7 & 53 & 34 & 34 & 121 & 356.09 & 425.31 & 647.03 & 1428.43 \\
\hline İtalia & 27.3 & 10.5 & 22.6 & 28.7 & 44 & 43 & 36 & 123 & 347.10 & 583.37 & 727.33 & 1657.80 \\
\hline $\mathrm{K}-7$ & 17.3 & 10.5 & 25.6 & 28.7 & 54 & 46 & 33 & 133 & 383.43 & 642.50 & 688.71 & 1714.63 \\
\hline Kabarcık & 12.3 & 13.5 & 02.7 & 08.8 & 62 & 50 & 37 & 149 & 436.26 & 747.65 & 727.92 & 1911.83 \\
\hline Kara Erik & 14.3 & 09.5 & 05.7 & 19.8 & 56 & 57 & 45 & 158 & 380.01 & 861.55 & 873.00 & 2114.55 \\
\hline Kozak Beyazı & 20.3 & 14.5 & 16.6 & 18.7 & 55 & 33 & 32 & 120 & 436.25 & 431.19 & 628.60 & 1496.03 \\
\hline Kozak Siyahı & 22.3 & 11.5 & 23.6 & 31.7 & 50 & 43 & 38 & 131 & 386.72 & 587.15 & 770.40 & 1744.28 \\
\hline Michelle Palieri & 20.3 & 15.5 & 01.7 & 02.8 & 56 & 47 & 32 & 135 & 454.56 & 692.19 & 644.38 & 1791.13 \\
\hline Muscat Bleu & 10.3 & 04.5 & 15.6 & 21.7 & 55 & 42 & 36 & 133 & 333.64 & 533.17 & 702.11 & 1568.93 \\
\hline Muscat R.V. & 08.3 & 03.5 & 19.6 & 15.7 & 56 & 47 & 26 & 129 & 329.61 & 607.48 & 524.81 & 1461.91 \\
\hline Perlette & 12.3 & 14.5 & 17.6 & 15.7 & 63 & 34 & 28 & 125 & 449.62 & 446.99 & 555.30 & 1451.91 \\
\hline Prima & 27.3 & 09.5 & 09.6 & 06.7 & 43 & 31 & 27 & 101 & 335.67 & 386.75 & 475.19 & 1197.60 \\
\hline Reçel Üzümü & 23.3 & 10.5 & 28.6 & 21.8 & 48 & 49 & 58 & 155 & 367.61 & 696.85 & 1062.77 & 2127.22 \\
\hline Red Globe & 24.3 & 10.5 & 25.6 & 04.8 & 47 & 46 & 40 & 133 & 363.12 & 642.50 & 804.70 & 1810.31 \\
\hline Regent & 11.3 & 03.5 & 21.6 & 18.7 & 53 & 49 & 27 & 129 & 320.02 & 639.17 & 550.63 & 1509.81 \\
\hline Sultan Ç. & 14.3 & 11.5 & 29.6 & 02.8 & 58 & 49 & 34 & 141 & 406.41 & 700.66 & 696.22 & 1803.29 \\
\hline Superior S. & 12.3 & 06.5 & 13.6 & 08.7 & 55 & 38 & 25 & 118 & 349.56 & 480.77 & 476.67 & 1307.00 \\
\hline Thompson S. & 13.3 & 12.5 & 27.6 & 23.7 & 60 & 46 & 26 & 132 & 422.95 & 648.89 & 533.46 & 1605.30 \\
\hline Trakya İlkeren & 24.3 & 07.5 & 07.6 & 03.7 & 44 & 31 & 26 & 101 & 330.72 & 377.13 & 466.82 & 1174.67 \\
\hline Uslu & 18.3 & 06.5 & 03.6 & 01.7 & 49 & 28 & 28 & 105 & 339.11 & 333.80 & 476.77 & 1149.68 \\
\hline Verigo & 26.3 & 13.5 & 22.6 & 28.7 & 48 & 40 & 36 & 124 & 395.62 & 539.76 & 727.33 & 1662.71 \\
\hline Victoria & 13.3 & 06.5 & 04.6 & 07.7 & 54 & 29 & 33 & 116 & 349.61 & 347.19 & 585.85 & 1282.66 \\
\hline Yalova İncisi & 22.3 & 13.5 & 08.6 & 07.7 & 52 & 26 & 29 & 107 & 415.35 & 316.40 & 529.94 & 1261.70 \\
\hline
\end{tabular}

*:Gün.ay; **: U: Uyanma; B: Ben düşme; Ç: Tam çiçeklenme; O: Olgunluk. 
sahip olmuştur. $\mathrm{Bu}$ tip farklılıkların ortaya çıkmasında, ekolojilerin ve asmaların (yaşı, anacı, terbiye sistemi vb) yapısından kaynaklanan farklılıkların yanı sıra araştırıcıların, özellikle olgunluk zamanını değişik şekillerde saptamasının da etkili olduğu düşünülmektedir (Çelik ve ark. 2005; Özdemir ve Tangolar 2005; Gazioğlu Şensoy ve ark. 2009). Aynı çeşidin değişik yörelerdeki hasat tarihleri esas alınarak yapılan genel bir karşılaştırmada (Yörenin uyanma olgunlaşma dönemi EST değerleri parantez içerisinde dg olarak belirtilmiştir), Antalya (3360) ekolojisindeki üzümlerin olgunlaşmasının, çeşitlere göre değişmek üzere; Adana (2898)'dan 0-2 hafta (hf), Maraş (2146)'tan 1 hf, Diyarbakır (2681)'dan 2-3 hf, Manisa (2705)'dan 3 hf, Kalecik (1970)'den 3-6 hf, Edirne (1885)'den3-7 hf, Tekirdağ (1872)'dan 3-8 hf, Tokat (1599)'tan 4-6 hf, Samsun (1996)'dan 4-8 hf, Van (1307)'dan 4-8 hf, Sakarya (1530)'dan 8 hf kadar daha erkenci olduğu görülmüştür (Çelik ve ark. 1998; Çelik ve ark. 2005; Özdemir ve Tangolar 2005; Gazioğlu Şensoy ve ark. 2009; Sabanc1 2009; Sağlam ve ark. 2009; Köse 2014, Altun 2015; Kılıç ve ark. 2016; Toprak Özcan ve Kesgin 2016). Buradan da anlaşılabileceği gibi, bir çeşidin farklı ekolojilerdeki olgunlaşma tarihi veya EST isteği birbirine yakın olabileceği gibi, oldukça uzak da olabilmektedir. $\mathrm{Bu}$ durum, yetiştirme koşulları, ekoloji ve ölçüm metodu farklılıklarının yanı sıra çeşitlerin değişik ekolojik koşullara karşı olan farklı tepkilerinden de kaynaklanabilir.

\subsection{Antalya ili genelindeki yörelere ait EST potansiyelleri}

Araştırma bağına ait EST potansiyeli 3359.6 dg olarak tespit edilmiştir (Çizelge 2). Denemenin yapıldığı bağ, Çelik ve ark. (1998) tarafindan yapılan sınıflandırmaya göre 3359.6 dg'lik yöresel EST değeri ile sıcak bölgede yer almıştır. Meteoroloji istasyonlarından alınan verilerle yapılan hesaplamalarda ise Antalya ili genelindeki diğer yörelerde 1 Nisan-31 Ekim tarihleri arasındaki EST potansiyellerinin 408.8-3276.9 dg arasında değiştiği saptanmıştır (Çizelge 2).

Çizelge 2. Meteoroloji istasyonlarının bulunduğu yörelerin koordinatları ve EST potansiyelleri.

Table 2. Coordinates and EHS potentials of locations where meteorological stations are placed in Antalya.

\begin{tabular}{|c|c|c|c|c|c|}
\hline İstasyon Adı & Rakım (m) & Enlem & Boylam & 2017 EST $(\mathrm{dg})$ & Uzun yıllar EST (dg) \\
\hline Antalya merkez (Kampüs) & 50 & 36.89 & 30.63 & 3359.6 & ----------- \\
\hline Alanya & 6 & 36.55 & 31.98 & 3276.9 & $3170.9(22)^{*}$ \\
\hline Manavgat & 38 & 36.78 & 31.44 & 3137.7 & $2976.3(22)^{*}$ \\
\hline Kaş & 153 & 36.20 & 29.65 & 3088.1 & $2985.2(22)^{*}$ \\
\hline Gazipaşa & 21 & 36.27 & 32.30 & 2936.8 & $2836.2(22)^{*}$ \\
\hline Kumluca & 60 & 36.36 & 30.29 & 2719.4 & $2760.0(10)^{*}$ \\
\hline Serik & 94 & 36.95 & 31.11 & 2531.3 & $2911.3(6)^{*}$ \\
\hline Gebiz Orman Sahası & 78 & 37.10 & 30.93 & 2461.0 & $3122.5(4)^{*}$ \\
\hline Çavdır Orman Sahası & 71 & 36.35 & 29.34 & 2334.0 & $2927.7(4)^{*}$ \\
\hline Karain Havacilık & 308 & 37.09 & 30.64 & 2263.3 & $2802.8(3)^{*}$ \\
\hline Beşkonak Orman Sahası & 142 & 37.14 & 31.19 & 2224.4 & $2861.1(4)^{*}$ \\
\hline Nebiler Orman Sahası & 266 & 36.95 & 30.60 & 2088.2 & $2717.7(4)^{*}$ \\
\hline İbradı & 1036 & 37.09 & 31.59 & 2075.5 & $2127.8(10)^{*}$ \\
\hline Kasaba Orman Sahası & 211 & 36.30 & 29.73 & 2006.8 & $2172.6(4)^{*}$ \\
\hline Elmalı & 1095 & 36.58 & 29.98 & 1940.2 & $1722.9(22)^{*}$ \\
\hline Korkuteli & 1017 & 37.05 & 30.19 & 1919.6 & $1692.2(22)^{*}$ \\
\hline Gündoğmuş Orman Deposu & 898 & 36.80 & 31.99 & 1851.0 & $2334.3(4)^{*}$ \\
\hline Murtiçi Orman Sahası & 508 & 36.86 & 31.77 & 1770.7 & $2231.2(4)^{*}$ \\
\hline Bük Orman Sahası & 489 & 36.97 & 30.43 & 1645.3 & $1915.8(4)^{*}$ \\
\hline Manavgat Orman Sahası & 998 & 36.86 & 31.67 & 1617.2 & -------------- \\
\hline Akseki & 1063 & 37.04 & 31.79 & 1550.3 & $1857.5(7)^{*}$ \\
\hline Dağbeli & 789 & 37.18 & 30.49 & 1516.9 & $1428.0(4)^{*}$ \\
\hline Akdağ Kovucak Mevki & 1001 & 36.59 & 30.25 & 1435.7 & $1932.5(2)^{*}$ \\
\hline Yuvacık Mevki & 1428 & 36.44 & 29.54 & 1256.7 & $1625.1(2)^{*}$ \\
\hline Ortabağ Mevki & 1423 & 36.45 & 29.79 & 1122.3 & $1555.2(2)^{*}$ \\
\hline Cevizli Tekebeli Mevki & 1420 & 37.24 & 31.77 & 1085.6 & $1494.8(2)^{*}$ \\
\hline Bedan Mevki & 1672 & 36.78 & 32.27 & 991.7 & $1369.1(2)^{*}$ \\
\hline \multirow[t]{2}{*}{ Kızılcadağ Mevki } & 1502 & 37.05 & 29.94 & 966.1 & $1387.9(2)^{*}$ \\
\hline & & ------ 90 & T SINIR & ----------- & \\
\hline Hacıyusuflar Mevki & 1720 & 36.89 & 29.89 & 819.4 & $1217.4(2)^{*}$ \\
\hline Elmalı Orman Sahası & 1311 & 36.58 & 29.98 & 758.5 & $1232.6(3)^{*}$ \\
\hline Yaylapalamut Mevki & 1637 & 36.48 & 29.51 & 743.0 & $1129.1(2)^{*}$ \\
\hline Çomaklı Mevki & 1719 & 37.30 & 30.17 & 695.1 & $1009.4(2)^{*}$ \\
\hline Bulanık Yaylası & 1870 & 36.62 & 29.66 & 628.4 & $1030.2(2)^{*}$ \\
\hline Gembos Ovası & 1500 & 37.25 & 31.47 & 612.7 & ------------- \\
\hline Saklıkent Kayak Merkezi & 1880 & 36.83 & 30.33 & 408.8 & -------------- \\
\hline
\end{tabular}

*:1995-2015 aras1 rasat yapılan y1l sayıs1. 
Çelik ve ark. (1998) tarafindan belirtilen ve EST değerleri esas alınarak yapılan iklim sınıflandırmasına göre yöreler 2017 verilerine göre aşağıdaki gruplarda yer almıştır: Merkez (Kampus), Alanya, Manavgat, Kaş, Gazipaşa, Kumluca, Serik, Gebiz Orman Sahası, Çavdır Orman Sahası, Karain Havacılık için sıcak iklim kuşağı; Beşkonak Orman Sahası, Nebiler Orman Sahası, İbradı, Kasaba Orman Sahası için sıcak-1lıman iklim kuşağı"; Elmalı, Korkuteli, Gündoğmuş Orman Deposu, Murtiçi Orman Sahası için ılıman iklim kuşağı; Bük Orman Sahası, Manavgat Orman Sahası, Akseki, Dağbeli, Akdağ Kovucak Mevki için serin iklim kuşağı; Yuvacık Mevki, Ortabă̆ Mevki, Cevizli Tekebeli Mevki, Bedan Mevki, Kızılcadağ Mevki için soğuk iklim kuşağı. Yöreler için tespit edilen EST potansiyellerinin, yöre rakımları ile karşılaştırılmasında; 1311 m rakımlı Elmalı orman deposunda olduğu gibi bazı yöreler için rakımına oranla beklenenden daha düşük (758.5 dg); $1672 \mathrm{~m}$ rakımlı Bedan yöresinin ise beklenenden daha büyük (991.7 dg) EST değerlerine sahip olduğu tespit edilmiştir (Çizelge 2). Bu durumun, yörelerin barındırabilecekleri mikro klimalardan ya da verilerin alındığı meteoroloji istasyonlarının bulunduğu konumun topografik özelliklerinden kaynaklanmış olduğu düşünülmektedir. Yüksek rakımlı bazı yörelerin 2017 yılı EST potansiyelleri 900 dg'ün altında kalmasına karşın, uzun yıllar ortalamasının bu değerin üstüne çıkması; 2017 yılının diğer yıllara göre nispeten daha soğuk geçtiğini göstermektedir. Ancak, yüksek rakımlı yörelerdeki EST değeri, bazı yıllarda eşik potansiyel değer olan 900 dg'ün üstüne çıkılsa bile, diğer yıllarda sonbahar erken donları nedeniyle üzümlerin soğuktan zarar görme riski yüksektir ve bu gibi yüksek yörelerde bağcılık yapılması önerilmez.
Yöre potansiyelleri ve çeşitlerin EST istekleri ile pratik bir çeşit-rakım kılavuzu hazırlanmıştır (Şekil 1). Bu kılavuzda, her bir katman içinde belirtilen çeşitlerin, alt katmanlarda (rakım aralıklarında) rahatlıkla yetiştirilebileceği fakat üst katmanlarda riskli olduğu söylenebilir. Bir üst katmanda risk daha azdır (en üst katman hariç). İki üst katmanda yetiştirmek ise pek önerilmez. Böyle durumlarda çeşit ve yörenin EST değerlerini uzun yıllar rasatlarını esas alarak daha yakından incelemek ve eşleştirmekte yarar vardır.

\section{Sonuç ve öneriler}

Araştırmada, 34 farklı üzüm çeşidinin Antalya merkezdeki fenolojik evreleri ve EST istekleri tespit edilmiştir. İncelenen çeşitlerin mart ayında uyanmaya başladığı ve ağustos sonunda olgunlaşmalarını tamamladıkları saptanmıştır. Uyanmadan olgunlaşmaya kadar geçen süre, çeşitlere göre 101-158 gün arasında değişmiştir. Ayrıca farklı rakımlardaki 35 yörenin bağcılık için EST potansiyelleri belirlenmiştir. İncelenen yörelerden 7 si hariç diğerlerinin uygun çeşit seçmek koşuluyla, hava sıcaklıkları açısından bağcılık yapmaya elverişli olduğu belirlenmiştir. Çeşitler ile yörelerin, rakım ve EST değerleri karşılaştırmalı olarak bir şekil üzerinde eşleştirilmiş ve böylece üreticilere, bulundukları yöreye uygun çeşit seçiminde kolaylık sağlanmıştır Yapılan bu çalışmanın diğer iller için de gerçekleştirilerek, ülkemizin farklı yörelerinde yetiştirilmeye uygun üzüm çeşitlerinin haritasının çıkarılmasında yarar vardır. $\mathrm{Bu}$ durum, özellikle havza bazlı tarımsal üretim planlamasında ilgili kişilere büyük kolaylık sağlayacaktır.

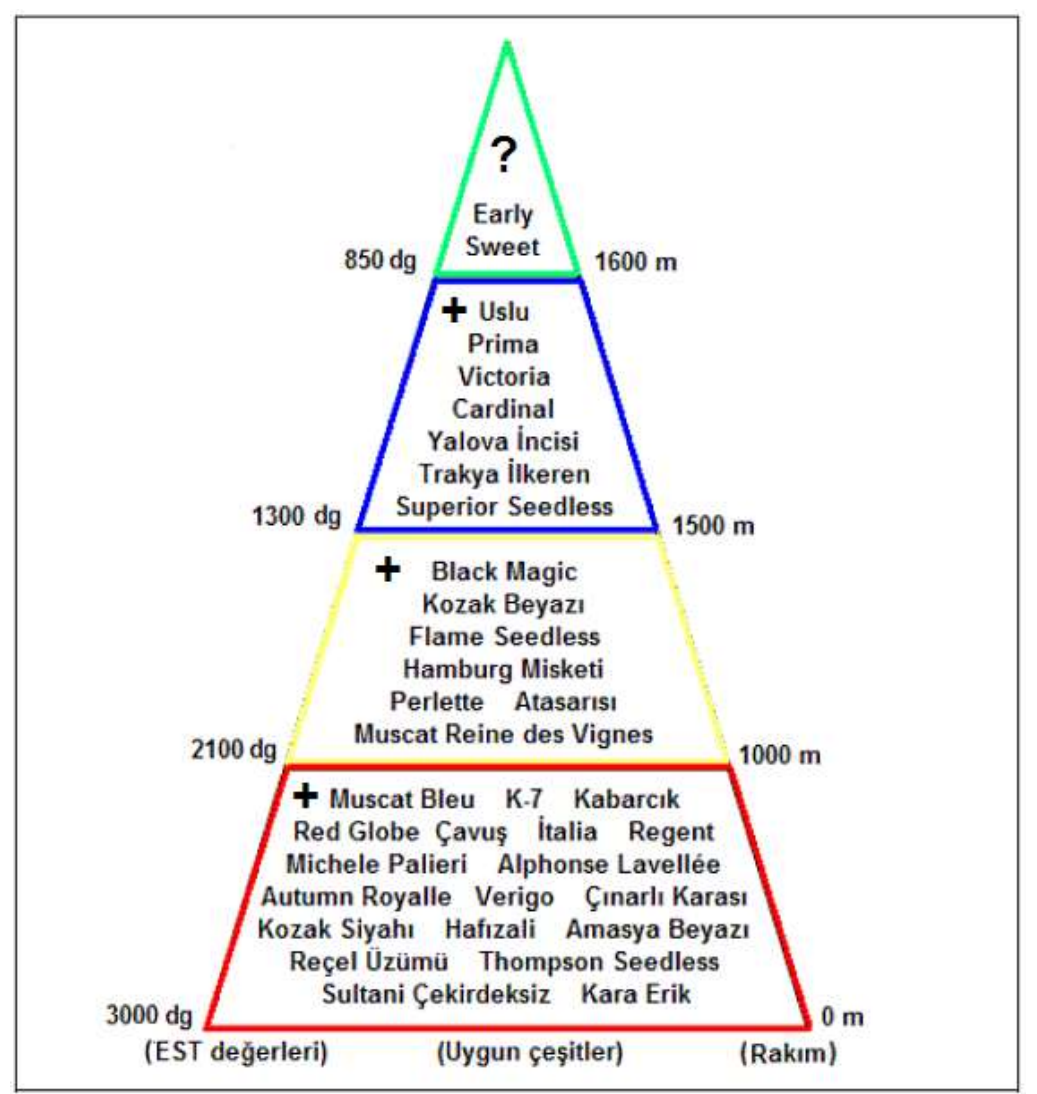

Şekil 1. Antalya ilinde rakıma göre yöreler için üzüm çeşidi seçim kılavuzu.

Figure 1. Grape cultivar selection guide for Antalya with various altitudes. 


\section{Teşekkür}

Bu çalışmayı Yüksek Lisans Tezi olarak FYL-2017-2696 nolu proje ile destekleyen Akdeniz Üniversitesi Bilimsel Araştırma Projeleri Koordinasyon Birimi'ne teşekkür ederiz.

\section{Kaynakça}

Altun AM (2015) Bazı önemli sofralık üzüm çeşitlerinin Sakarya/Taraklı ekolojisine adaptasyonu. Yüksek Lisans tezi, Gaziosmanpaşa Üniversitesi, Tokat, s. 48.

Amerine MA, Roessler EB (1958) Field testing of grape maturity. Hilgardia 28(4): 93-114.

Cemeroğlu BS (2007) Gıda Analizleri. 4. Baskı, s. 480.

Çelik H, Ağaoğlu YS, Fidan Y, Marasalı B, Söylemezoğlu G (1998) Genel Bağcılık. Sun fidan A.Ş. Mesleki Kitaplar Serisi: 1, s. 253.

Çelik H, Söylemezoğlu G, Çetiner H, Kunter B, Çakır A (2005) Bazı üzüm çeşitlerinin Kalecik (Ankara) koşullarındaki fenolojik özellikleri ile etkili sıcaklık toplamı (EST) isteklerinin belirlenmesi. Türkiye 6. Bağcılık Sempozyumu 2: 390-397.

Çelik S ( 2007) Bağcılık(Ampeloloji). Cilt 1. Tekirdağ, s. 428.

FAO (2007) Codex alimentarius. Fresh fruits and vegetables. Rome, pp. 185.

Gazioğlu Şensoy Rİ, Balta F, Cangi R (2009) Bazı sofralık üzüm çeșitlerinin Van ekolojik koșullarındaki etkili sıcaklık toplamı değerlerinin belirlenmesi. Harran Üniversitesi Ziraat Fakültesi Dergisi 13(3): 49-59.

Gu S (2016) Growing degree hours - a simple, accurate, and precise protocol to approximate growing heat summation for grapevines. International Journal of Biometeorology 60: 1123-1134.

Jacob HE, Winkler AJ (1950) Grape growing in California. Circular 116. California Agricultural Extension Service, College of Agriculture, University of California, Berkeley, California, pp. 80.

Kamiloğlu Ö, Atak A, Kiraz ME (2014) Bazı üzüm çeşitleri ve melez çeşit adaylarının Hatay/Amik ovası koşullarındaki performanslarının belirlenmesi. Türk Tarım ve Doğa Bilimleri Dergisi 1(3): 413-420.

Kaya M, Özdemir G (2015) Bazı sofralık üzüm çeşitlerinin Diyarbakır koşullarındaki kalite özellikleri ile etkili sıcaklık toplamı isteklerinin belirlenmesi. Selçuk Tarım ve Gıda Dergisi (Özel sayı) 27: 199-209.

Kılıç D, Topal H, Kaya Y, Başaran B, Yağcı A, Cangi R (2016) Bazı erkenci üzüm çeşitlerinin Tokat merkez koşullarına adaptasyonu. VII. Ulusal Bahçe Bitkileri Kongresi 2: 678-682.
Kök D, Çelik S (2003) Bazı şaraplık üzüm çssitlerinin etkili sıcaklık toplamı gereksinimlerinin belirlenmesi ve bunun kalite özellikleri üzerindeki etkisi. Trakya Üniversitesi Bilimsel Araştırmalar Dergisi 4(1): 23-27.

Köse B (2014) Phenology and ripening of Vitis vinifera L. and Vitis labrusca L. varieties in the maritime climate of Samsun in Turkey's Black Sea region. South African Journal of Enology and Viticulture 35(1): 90-102.

OIV (2001) Descriptor list for grape varieties and Vitis species. http://www.oiv.int/public/medias/2274/code-2e-edition-finale.pdf. Erişim 30 Ekim 2017.

Özdemir G, Tangolar S (2005) Diyarbakır ve Adana koşullarında yetiştirilen bazı sofralık üzüm çeşitlerinde fenolojik devreler ile etkili sıcaklık toplamı değerleri ve bazı kalite özelliklerinin belirlenmesi. Türkiye 6. Bağcılık Sempozyumu 2: 446-453.

Sabancı A (2009) Kahramanmaraş Koşullarında Sofralık Üzüm Çeşit Adaptasyonu. Türkiye 7. Bağcılık ve Teknolojileri Sempozyumu 2: 306-311.

Sağlam M, Boz Y, Kiracı MA, Aydın S (2009) Sofralık üzüm çeşitlerinin Trakya bölgesindeki değişik ekolojik koşullara uyumu. Türkiye 7. Bağcılık ve Teknolojileri Sempozyumu 2: 129-138.

Söğüt AB， Özdemir G (2015) Bazı şaraplık üzüm çeşitlerinin Diyarbakır ekolojisindeki fenolojik özellikleri ile etkili sıcaklık toplamı isteklerinin belirlenmesi. Selçuk Tarım ve Gıda Dergisi (Özel sayı) 27: 403-412.

Tangolar S, Eymirli S, Özdemir G, Bilir H, Tangolar SG (2002) Pozantı/Adana'da yetiştirilen bazı üzüm çeşitlerinin fenolojileri ile salkım ve tane özelliklerinin saptanması. Türkiye V. Bağcılık ve Şarapçılık Sempozyumu, Nevşehir, s. 372-380.

Toprak Özcan E, Kesgin M (2016) Bazı üzüm çeşitlerinin Manisa koşullarında fenolojik özellikleri ve etkili sıcaklık toplamı (EST) isteklerinin belirlenmesi. VII. Ulusal Bahçe Bitkileri Kongresi 2: 783-788.

Uzun Hİ, Barış C, Gürnil K, Özışık S (1995) Bazı yeni üzüm çeşitlerinin Antalya koşullarına adaptasyonu üzerine araştırmalar. Akdeniz Üniversitesi Ziraat Fakültesi Dergisi 8: 65-80.

Uzun Hİ (1997) Heat summation requirements of grape cultivars. Acta Horticulturae 441: 383-386.

Uzun Hİ (2006) Bağcılık. Akdeniz Üniversitesi. Ziraat Fakültesi Ders Notlar1. Yayın no: 5. Antalya, s. 170.

Winkler AJ, Cook JA, Kliewer WM, Lider LA (1974) General Viticulture: Second Revised Edition. University of California Press, Berkeley, California, pp. 710. 